Article

\title{
On the Right Track: Comfort and Confusion in Indoor Environments
}

\author{
Nina Vanhaeren*(D), Laure De Cock ${ }^{\mathbb{D}}$, Lieselot Lapon, Nico Van de Weghe ${ }^{\mathbb{D}}$, Kristien Ooms \\ and Philippe De Maeyer ${ }^{D}$
}

Department of Geography, Ghent University, Krijgslaan 281 (S8), 9000 Ghent, Belgium; laudcock.decock@ugent.be (L.D.C.); lieselot.lapon@ugent.be (L.L.); nico.vandeweghe@ugent.be (N.V.d.W.); kristien.ooms@ugent.be (K.O.); philippe.demaeyer@ugent.be (P.D.M.)

* Correspondence: nina.vanhaeren@ugent.be; Tel.: +32-9-247-4700

Received: 18 December 2019; Accepted: 20 February 2020; Published: 24 February 2020

\begin{abstract}
Indoor navigation systems are not well adapted to the needs of their users. The route planning algorithms implemented in these systems are usually limited to shortest path calculations or derivatives, minimalizing Euclidian distance. Guiding people along routes that adhere better to their cognitive processes could ease wayfinding in indoor environments. This paper examines comfort and confusion perception during wayfinding by applying a mixed-method approach. The aforementioned method combined an exploratory focus group and a video-based online survey. From the discussions in the focus group, it could be concluded that indoor wayfinding must be considered at different levels: the local level and the global level. In the online survey, the focus was limited to the local level, i.e., local environmental characteristics. In this online study, the comfort and confusion ratings of multiple indoor navigation situations were analyzed. In general, the results indicate that open spaces and stairs need to be taken into account in the development of a more cognitively-sounding route planning algorithm. Implementing the results in a route planning algorithm could be a valuable improvement of indoor navigation support.
\end{abstract}

Keywords: indoor wayfinding; cognition; navigation system; route planning algorithm; comfort; confusion

\section{Introduction}

Indoor navigation systems help people to navigate indoors. Different systems have already been developed and are running (e.g., NavCog, SafeExit4All, MazeMap, Drishti, CENSE) [1-5]. However, these solutions have been developed for specific user groups, buildings or events and, so far, have not yet resulted in a commonly known and applied system.

A considerable amount of research on indoor navigation has been published, but the subject is treated separately in different research fields, ranging from engineering (indoor positioning) (e.g., [6-15]), informatics (indoor modeling) (e.g., [16-19]), and architectural design (e.g., [20-23]), to psychology (analysis of spatial-related perceptual and cognitive processes) (e.g., [24-28]). Much of the current literature on navigation systems pays particular attention to the localization or other components of the system, while there has been little discussion about the optimization of route calculations.

Given that the applied route planning algorithms in the literature have been mentioned, which usually is not the case (e.g., [29]), these are mostly shortest path algorithms (e.g., Dijkstra, $A^{*}$ ) minimizing travel distance (e.g., [1,30-37]). In contrast to this practice, scholars disagree with the use of length optimized paths. First of all, people do not navigate Euclidian [38]. In contrast to the general assumption of a metric Euclidian structured cognitive map, Warren [38] argues that spatial relations of a mental map are connected topologically in a graph structure, and thus contests the existence of this 
Euclidian navigation. If people do not think in distances, why would they prefer the shortest path? Secondly, length-optimized paths can be unnecessarily complex, lack all logic (e.g., using complex intersections or avoiding the main walking areas) and, besides, these shortest paths are not always preferred by the users [39]. The shortest path between two locations is thus not necessarily the best way to reach our destination. With this research, we aim to contribute to the improvement of the usability of these navigation systems by examining how to adapt the paths along which people are navigated.

\section{Related Work}

\subsection{Alternative Path Algorithms}

For outdoor environments, several alternative route planning algorithms have been developed, such as the fewest turn path algorithm $[40,41]$ and the simplest instruction path algorithm [42]. Also, several attempts have been made to improve the path calculations for indoor environments. Most of the solutions adapt the costs in the edges or nodes and use the Dijkstra algorithm to minimize the cost. A simple solution was proposed by Khan et al. [35], who tried to optimize travel time based on estimated speeds, differentiating between regular walked segments and stairs. In related research on evacuation, the focus of path planning is on speed, but risk, population density, accessibility, user restrictions, and turns are also considered [2,20,43,44]. Swobodzinski et al. [45] proposed a Dijkstra algorithm that is adapted for blind people by integrating the landmarks and clues that support their wayfinding. Also, Kahale et al. [46] developed a route planning algorithm that minimalizes arduousness for people based on specific physical characteristics of the users restricting the mobility of the users (e.g., blindness, wheelchair). Moreover, Dudas et al. [47] presented a formal presentation of a path algorithm that calculates the most feasible and comfortable path based on specified user preferences. However, they did not elaborate on feasibility and comfort.

As shown above, applied research on indoor routing algorithms generally focuses on specific situations, such as evacuations, or on users with specific needs, such as impaired people. The commonly applied principle in navigation support for ordinary users without specific needs is still the shortest path, minimizing distances. Zhou et al. [48] tried to fill this gap by developing an algorithm for ordinary users in regular situations. They included path complexity, crowded degree and blocking events in the Dijkstra algorithm. However, there has been little discussion about which factors to include. Moreover, they limited the complexity assessment of the path to the total number of turns of the path. Furthermore, "crowded degree" and "blocking events" are not included in common indoor spatial models.

\subsection{Cognitive Processes}

Wayfinding is the process of finding your way to a destination in a familiar or unfamiliar setting using environmental cues [49] and is a highly complex cognitive operation [50]. To adapt the routes adequately, understanding of the cognitive processes during wayfinding is necessary. Furthermore, wayfinding is a component of navigation and constitutes of complex cognitive processes, such as planning and decision-making based on previously gained and ad hoc knowledge of the environment [51]. Multiple cognitive models of wayfinding refer to route planning and execution. Spiers and Maguire [52] describe wayfinding as an iterative process of information processing, planning, execution, and potential re-planning in case expectations are violated as the environment is perceived. Fundamentally, as stated by Farr et al. [49], it can be broken down into three interrelated processes: decision making, decision execution, and information processing, of which the latter entails environmental perception and cognition which support the previous two processes. The cognitive processes occurring during the wayfinding process interact with each other, the navigator and the environment.

In this study, we mainly focused on information processing, which involves attention, perception, and memory. More specifically, we focused on environmental perception, which is commonly known 
as awareness about the environment and the act of apprehending the environment through the senses [53]. It is thus an interaction between an individual and their surroundings. The final step in the perception process is image formation, which is defined as the process of acquiring information about the surroundings, resulting in mentally stored images about the perceived environment. It is defined by the environment, previous knowledge, personal characteristics, and abilities, and the task [54].

Through interaction with the environment, people acquire spatial knowledge. In the first place, humans achieve landmark knowledge, before acquiring route knowledge and survey knowledge [55]. The environmental knowledge of a person is defined by how the information is gained and stored, and how it can be recalled [54]. Therefore, the landmarks play a central role in how information is acquired and, by extension, in the other cognitive processes of wayfinding. Because landmark-based wayfinding is known to be effective, landmarks should be included in route instructions $[55,56]$. Current studies focus mainly on the saliency of landmarks (e.g., [56-59]).

As can be seen, during the wayfinding process, a dynamic interplay occurs between the environment, the navigator, and these multiple cognitive processes [60]. The changes in the environment during the wayfinding process update their view and change their perception [61]. In fact, it is the interaction between the individual and the environment that determines the difficulty of a wayfinding task [62]. More specifically, the spatial structure of the building, the cognitive maps, the strategies, and the spatial abilities of the navigators contribute to the difficulty of wayfinding [18]. Both the environmental and the personal characteristics thus shape the cognitive processes during wayfinding (e.g., perception, working memory, and decision making).

Specifically for the indoor environment, it is known that its specific environmental characteristics related to the vertical movement and the influence of architectural characteristics have a considerable effect on wayfinding [63-66], in comparison to the outdoor environment.

Also, personal characteristics play a role in this wayfinding process. In other words, besides the environment, also mood, emotions, and affect have an influence on these processes [67]. Studies show that since emotions or affect influence our perception and cognitive abilities, they, in turn, affect our memory and wayfinding capabilities (e.g., [67-69]). For instance, positively or negatively affected landmarks, compared to neutral emotional landmarks, enhance wayfinding performance $[70,71]$ and cognitive map development. Also, it was found that stress and anxiety negatively influence wayfinding performance [72,73]. Although it is generally known that affect influences wayfinding, little attention has been devoted to using people's affective responses to environments to enhance route planning [69]. Some spaces might induce stress or disgust people, while others are attractive and enjoyable [69].

\subsection{Indoor Navigation Situations}

Different methods exist to determine turns and intersections and to quantify their complexity. Traditionally, intersection complexity is quantified by the number of branches at an intersection [74]. Fogliaroni et al. [75] append the shape of the intersections to the complexity assessment of the intersections. In our study, we limited the type of intersections and turns to 90 degrees turns on simple L- and T-junctions.

In wayfinding research, doors have been reported in different contexts in the literature, but their effects on wayfinding are not actively researched as far as we know. In research on landmarks, doors are considered to be functional landmarks [76,77]. Furthermore, when modeling indoor environments or wayfinding behavior, doors are considered to be both the entrance to the room-and thus the origin of the user-and the destination of the user when crossing a room [78]. They are the destinations within the room [79], but also give access to a new environment after it. Liu and Zlatanova [80] applied this principle in their proposed door-to-door routing algorithm, since from a door to the next door is the most direct way of walking. In some spatial models, the notion of "door" is included, but limited to the classification of a transition node [1].

Open spaces have an impact on wayfinding in different ways. The first one is related to the degree of movement. It is commonly known that pedestrians have greater freedom in movement 
in comparison to all other transport modes [81,82]. But also on a smaller scale, within the indoor environment, the degree of freedom differs: in corridors, people go more or less straight following the medial axis, while in open spaces, people move more freely. Furthermore, it is widely accepted in the literature $[83,84]$ that these open spaces provide visual access to the building which facilitates the legibility of the building [85] and orientation [86]. In contrast, this freedom of movement induces difficulties in modeling open spaces and modeling the routing in these spaces, which have been outlined and examined in a number of studies (e.g., $[87,88])$.

Stairs are seen as one of the major causes of navigation problems and staircase design, in particular, was identified as a major wayfinding obstacle [66]. Besides being studied in wayfinding research, they are also included in path planning algorithms for the mobility of impaired people [89]. They are also considered to be functional landmarks [76]. Furthermore, several studies have been devoted to modeling them in spatial models $[78,90,91]$, and when included in spatial models they are sometimes considered as transition nodes [1].

\subsection{Research Goal}

To diminish the mental demand of the wayfinding task allowing individuals to focus on other aspects than the navigation [92], indoor wayfinding systems have to be adapted. Adapting the path along which people are guided could substantially improve indoor navigation systems. Paths need to be planned in such a way as to maximize usability and minimize the risk of getting lost. These easier-to-follow routes reduce the risk of getting lost, require a smaller effort, guide in recalling routes, and are overall perceived to be more comfortable [93]. To develop a route planning algorithm specifically for the indoor environment that calculates these easier routes, understanding wayfinding processes is required. To learn how to adapt the route planning algorithms adequately, this paper attempts to answer the question regarding which elements should be included in this improved route planning method. Hence, to answer this question, a focus group discussion was organized as an exploratory study. Complementarily, and more specifically, by examining the comfort and confusion perception of specific indoor navigation situations in an online survey, we aim to contribute to the answer to the question above. This study seeks to address the relationship between the aforementioned situations and people's comfort and confusion ratings. Since the usability of a product is of substantial importance when developing it [94], user testing is incorporated in the design process of this algorithm by executing an online survey.

This paper examines the perception of comfort and confusion in specific wayfinding situations based on the results of an online survey. The remainder of the paper commences with the study setup (Section 3.1), the data acquisition (Sections 3.2 and 3.3), and the data analysis methods (Section 3.4). The subsequent section constitutes the results (Section 4). In the consecutive discussion section (Section 5), the results are put in context by relating them to existing literature. Finally, the conclusion gives a brief summary and critique of the findings (Section 6).

\section{Materials and Methods}

\subsection{Study Design and Setup}

First, an exploratory literature study and focus group were conducted. Based on the coinciding results, an online survey was set up examining comfort and confusion perceptions of specific indoor wayfinding situations. The workflow of the study is shown in Figure 1. 


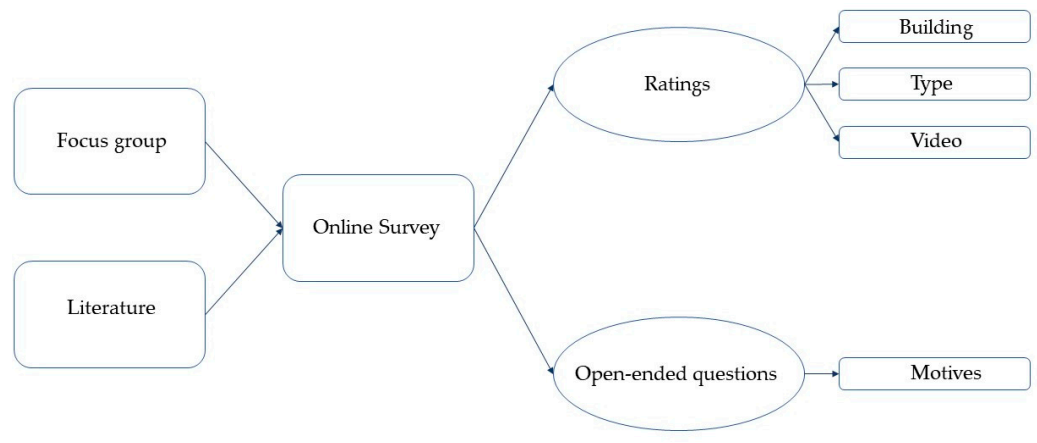

Figure 1. Diagram study design.

\subsubsection{Exploratory Study}

To develop a well-designed online survey, a focus group discussion was conducted. The focus group aimed to explore the problem of route planning in the indoor environment. The results helped to explore the problem and facilitated an adequate setup of our online survey. To structure the multiple discussions of the focus group, the so-called GPS-method, a by-a-rotating-wheel-guided brainstorm method developed by the Flanders District of Creativity, was employed [95]. The applied GPS-method respects the general design rules of focus groups as recommended by Freitas et al. [96] and Krueger and Casey [97]. The method is specially designed to encourage active participation and limits the involvement of the moderator which is particularly recommended when the objective of the research is exploratory [95]. The focus group comprised six academic researchers and experts with diverse academic backgrounds, all of them working on research topics related to indoor navigation in different research areas, such as psychology, informatics, geography, and architectural design. A pilot study with six participants was conducted to evaluate the method. Two researchers moderated the sessions; the main moderator guided the discussion (e.g., asking questions, tracking time) and the assistant-moderator took notes. The discussion session took approximately three hours and consisted of a short introduction and different discussion rounds.

In the focus group discussions, a broad range of topics was tackled, providing an overview of aspects that should be considered in the further development of a cognitively-sounding route planning algorithm. The discussion topics coincided with aspects covered in existing literature, such as Weisman [63] and Hölscher et al. [66]. In the exploratory focus group, the same aspects emerged, and thus our findings from the literature were confirmed. In essence, we can conclude from the discussions that indoor wayfinding processes have to be studied further on different levels. On the local level, specific environmental characteristics can increase the complexity of the wayfinding process, for instance at decision points, whereas on a more global level, the overall structure of the environment [63] affects complexity as well. These results are in line with the research design of Li and Klippel [98]. In other words, when considering wayfinding complexity, not only the local structure, but also the overall environmental structure, has a considerable impact. We decided to focus on the local level for our current study, and thus an online survey was executed focusing on local indoor environmental characteristics.

\subsubsection{Stimuli}

As argued by Emo [99], a major component of human movement and interaction in the built environment is determined by the spatial structure of these surroundings but to date, no clear definition of these structures exists. The selection of the situations in the videos was based on existing literature and the findings of the focus group discussions. 35 different situations with varying intersections, staircases, and door types were selected. Short videos depicting these different navigation situations were recorded in various complex buildings (i.e., the university hospital and three different university campus buildings) differing in appearance (Figure 2). UZ, the Ghent University Hospital, is a complex 
building consisting of a renovated part with bright and wide hallways, but also an older part with darker and narrower corridors originating from the 1950s. The Plateau, housing the Faculty of Engineering and Architecture, is a 19th-century Neoclassical building. Due to a lack of space during the 20th century, the building was expanded by constructing extra floors and erecting new buildings in the courtyard. This resulted in an exceptionally complex building with many semi-floors, dead ends, and so on. Tweekerken, where the Faculty of Economics is based, was designed in the 70s as a "patio and terrace construction" in line with the concept of a "walking university" and a university as a meeting place. For that reason, many outdoor spaces were provided, such as indoor courtyards and terraces. The Dunant building was renovated in 2005 and it now contains an older part and an entirely new wing.

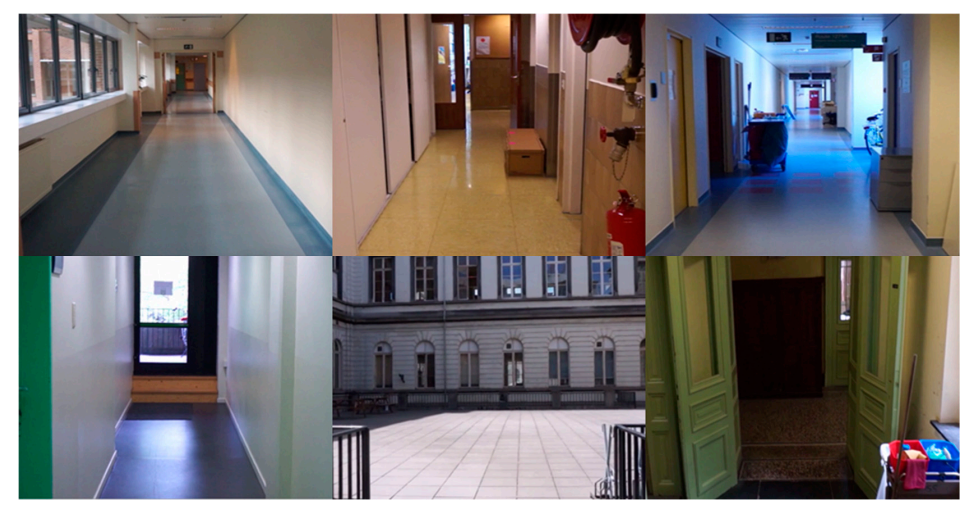

Figure 2. Screenshots videos. From left to right: video 5, 8, 12, 18, 34, 13.

The videos of situations in these buildings were recorded from the navigator's perspective. Before embedding the videos in the online survey, the sound was eliminated. To limit the workload for the participants, videos were shortened by accelerating them to a still visually comfortable speed $(\times 1.25)$, resulting in a video length varying between $7 \mathrm{~s}$ and $34 \mathrm{~s}($ mean $=17 \mathrm{~s})$.

\subsection{Procedure}

In the online survey, the participants were told to watch the videos and interpret the situations as if they were navigating through the building. After watching the videos, the participants had to rank their comfort level and confusion level of these situations on a 5-point Likert scale, by answering these questions: (1) How comfortable do you feel about the situation you just saw? and (2) How confusing is the situation you just saw? A definition of both concepts, based on the Oxford Dictionary, was provided in the instructions:

- “Comfortable: enjoying physical and mental comfort (free from stress, tension or doubt)"

- "Confusing: disturbing in mind, cause to lose the sense of time or place"

The "confusion" rating is related to the complexity of the situation. Comfort can be seen as the feasibility and the preferability of the situation estimated by the user [47]. Higher comfort ratings thus reflect enjoyable or preferable situations.

After ranking, the test subjects had to specify their motives for their given ranking: "Based on which criteria (characteristics, feelings ... ) did you rank the comfort/confusion level of the situation in the video?" General demographic information and characteristics (i.e., age, gender, education level) of each participant were collected as well.

\subsection{Data Collection}

The online survey was published on Amazon Mechanical Turk to reach a wide range of target users. One human intelligence task (HIT) consisted of two videos with two rankings and the open-ended questions. Participants chose how many HITs they completed. They were been rewarded 0.05 US Dollars per completed and approved HIT. 


\subsection{Data Analysis and Statistics}

\subsubsection{Dataset}

The HITs were rejected if answers to the general questions (e.g., gender, age, education level) were inconsistent for the same participant or if numeric or no answer was given to the open questions. The dataset consisted of rows containing HITs of two videos and its answers, i.e., ratings and open-ended questions for both videos. To analyze the data, this dataset was transformed into a dataset containing the watched videos, the ratings, and answers per row.

\subsubsection{Motives}

To select the most frequently mentioned words, the relative frequency, rather than the absolute frequency, was calculated. A cut off value of $0.1 \%$ was employed to select the most frequently mentioned words, resulting in a list of 174 words for comfort level and of 182 words for confusion level. Thereafter, to be able to analyze these lists, they were classified into different categories.

For this reason, a coding scheme (Table 1) was created following a standardized method [100]. An initial coding schema to classify the words into categories was developed and re-evaluated by the research team. Subsequently, this schema was validated by two researchers not involved in the study. The inter-coder reliability of the coders was evaluated using the Cohen's Kappa-coefficient K which does not just represent the proportion of the corresponding codes with respect to all codes, but additionally corrects for marginal frequencies and defines the associations as the relative proportion of corresponding codes. A reliability of $\mathrm{K}=0.67$ was achieved between the two independent coders, which is considered as substantial [101]. During the subsequent analysis, the proportions of the coded categories of the word lists were compared.

Table 1. Coding scheme.

\begin{tabular}{ccc}
\hline Code & Description & Examples \\
\hline Setup & $\begin{array}{c}\text { Related to the survey setup (video, words from } \\
\text { questions and instructions) }\end{array}$ & Speed, shaky, comfortable \\
\hline Colors/lightning & Related to the colors or lightning & Bright, red \\
\hline Social & Referring to (the presence or lack of) other people & Someone, nobody \\
\hline Actions & Verbs (or derivatives) related to navigation & Moving, walking \\
\hline Environmental elements & Tangible objects in the environment & Door, wall \\
\hline Places & Referring to locations & Hallway, school, environment \\
\hline Spatial Descriptions & Other words (nouns, adverbs or adjectives) with & Narrow, outside, above, path \\
\hline Non-spatial Descriptions & Nouns, adverbs or adjectives without a spatial \\
component & Nice, anxiety \\
\hline Other & Any other words & Seems, appear, just, and \\
\hline
\end{tabular}

\subsubsection{Central Tendency and Variability of the Ratings}

To be able to inspect the central tendency and the variability of the data, a frequency table was derived from the resulting dataset and summary statistics were calculated. The interquartile ranges (IQR), representing the variability, were also determined.

\subsubsection{Differences between groups}

In addition, possible rating differences between different groups (e.g., building, type, video) were researched using the Kruskal-Wallis $\mathrm{H}$ test. This non-parametric test detects if at least two groups differ from each other. Thereafter, if from the Kruskal-Wallis test it could be concluded that at least two groups were mutually different from each other, a post hoc Dunn test was performed to detect which 
groups exactly mutually differ. The Kruskal-Wallis $\mathrm{H}$ test, in combination with the Dunn test, enables us to determine rank-based which distributions of groups statistically differ from each other.

\section{Results}

\subsection{Dataset}

2839 HITs were submitted, of which 1025 were rejected. The rejected responses were eliminated from the initial dataset. On average, participants worked $238.4 \mathrm{~s}$ on one HIT. 905 unique participants worked on the HITs, of which 471 participants were female (52.2\%). Their ages ranged between 18 and 80 years old $(M=35, S D=12)$. Participants with varying levels of educational experience were reached, i.e., from elementary school to academic degrees.

The dataset of HITs (of two videos each) was transformed, resulting in a dataset representing the watched videos $(n=3628)$. Every video was watched and scored at least 84 times $(M=91)$. Five randomly chosen videos were assigned to twice as many of the participants. Half of the responses to these five videos were separated from the dataset and constitute a validation dataset. No statistical differences were found between the control and the actual dataset (see Table 2). After removing the rejected HITs, restructuring the dataset, and eliminating the validation data, the resulting dataset consisted of 3174 rows, representing the video observations (video number, ratings, and answers).

Table 2. Kruskal-Wallis $\mathrm{H}$ for the actual and validation dataset.

\begin{tabular}{cccccccc}
\hline \multirow{2}{*}{ Variable } & df & \multicolumn{3}{c}{ Comfort } & \multicolumn{3}{c}{ Confusion } \\
\cline { 3 - 8 } & & $\mathbf{n}$ & $\mathbf{H}$ & $\mathbf{p}$ & $\mathbf{n}$ & $\mathbf{H}$ & $\mathbf{p}$ \\
\hline actual dataset & 1 & 3173 & 1.209 & 0.271 & 3172 & 2.114 & 0.146 \\
validation dataset & & 453 & & & 452 & & \\
\hline
\end{tabular}

${ }^{*}$ Significant on the $95 \%$ confidence level.

\subsection{Motives}

The analysis of the open-ended questions provides us insight into which aspects play a role in people's perception of comfort and confusion in the presented indoor situations. In Table 3, the proportions of the categories of the most frequently mentioned words are presented. We note a large proportion of words referring to non-spatial descriptions and meaningless words ("other"). The categories referring to words with a spatial component (spatial descriptions, environmental elements, places) comprise a large proportion of the most frequently mentioned words (Table 3 , lines 5 , 6, 7). Participants referred more to "environmental elements", "spatial descriptions", and "other" when evaluating confusion (Table 3, lines 5, 7,9). In contrast, when evaluating comfort level, more words of the categories "colors/lightning", "social", and "non-spatial descriptions" are used to motivate their ranking (Table 3, lines 2, 3, 8).

Table 3. Proportions of the categories of the most frequent words.

\begin{tabular}{|c|c|c|c|c|c|c|c|}
\hline & & \multicolumn{2}{|c|}{ Comfort (\%) } & \multicolumn{2}{|c|}{ Confusion (\%) } & \multicolumn{2}{|c|}{$\Delta$ (= Comfort - Confusion $)$} \\
\hline & & Coder 1 & Coder 2 & Coder 1 & Coder 2 & Coder 1 & Coder 2 \\
\hline 1 & Setup & 7.51 & 10.98 & 5.52 & 10.50 & 1.99 & 0.49 \\
\hline 2 & Colors/lightning & 4.62 & 4.05 & 3.31 & 2.76 & 1.31 & 1.28 \\
\hline 3 & Social & 2.89 & 3.47 & 1.66 & 1.66 & 1.23 & 1.81 \\
\hline 4 & Actions & 5.20 & 5.20 & 4.97 & 5.52 & 0.23 & -0.32 \\
\hline 5 & Environmental elements & 3.47 & 2.31 & 3.87 & 3.87 & -0.40 & -1.56 \\
\hline 6 & Places & 5.78 & 8.67 & 5.52 & 8.29 & 0.26 & 0.38 \\
\hline 7 & Spatial Descriptions & 14.45 & 12.14 & 16.57 & 16.02 & -2.12 & -3.88 \\
\hline 8 & Non-spatial Descriptions & 28.90 & 26.59 & 26.52 & 16.57 & 2.38 & 10.02 \\
\hline 9 & Other & 27.17 & 26.59 & 32.04 & 34.81 & -4.88 & -8.22 \\
\hline
\end{tabular}




\subsection{Central Tendency and Variability of the Ratings}

A frequency table was derived from the resulting dataset and summary statistics were calculated (Table 4). The median for comfort level ranges between 3.00 and 4.00, and for confusion level between 3.00 and 5.00. The interquartile ranges (IQR), representing the variance of both the comfort level and confusion level, range between 1.00 and 3.00 .

Table 4. Descriptive statistics.

\begin{tabular}{|c|c|c|c|c|c|c|c|}
\hline \multirow{2}{*}{ Video } & \multirow{2}{*}{ Count } & \multicolumn{3}{|c|}{ Comfort } & \multicolumn{3}{|c|}{ Confusion } \\
\hline & & Modus & Median & IQR & Modus & Median & IQR \\
\hline 1 & 84 & 5.00 & 4.00 & 2.00 & 5.00 & 4.00 & 2.00 \\
\hline 2 & 85 & 5.00 & 4.00 & 2.00 & 5.00 & 5.00 & 2.00 \\
\hline 3 & 95 & 5.00 & 4.00 & 2.00 & 5.00 & 4.00 & 2.00 \\
\hline 4 & 89 & 5.00 & 4.00 & 2.00 & 5.00 & 4.00 & 2.00 \\
\hline 5 & 91 & 5.00 & 4.00 & 1.00 & 5.00 & 4.00 & 2.00 \\
\hline 6 & 90 & 5.00 & 4.00 & 2.00 & 5.00 & 4.00 & 2.00 \\
\hline 7 & 96 & 5.00 & 3.50 & 3.00 & 5.00 & 4.00 & 3.00 \\
\hline 8 & 89 & 4.00 & 4.00 & 1.00 & 3.00 & 3.00 & 1.00 \\
\hline 9 & 93 & 5.00 & 4.00 & 2.00 & 5.00 & 4.00 & 2.00 \\
\hline 10 & 93 & 5.00 & 4.00 & 2.00 & 4.00 & 4.00 & 2.00 \\
\hline 11 & 95 & 5.00 & 4.00 & 2.00 & 5.00 & 3.00 & 2.00 \\
\hline 12 & 88 & 4.00 & 4.00 & 2.25 & 5.00 & 3.00 & 3.00 \\
\hline 13 & 87 & 5.00 & 4.00 & 2.00 & 3.00 & 3.00 & 1.50 \\
\hline 14 & 95 & 5.00 & 4.00 & 2.00 & 4.00 & 4.00 & 2.00 \\
\hline 15 & 90 & 5.00 & 4.00 & 2.00 & 5.00 & 4.00 & 2.00 \\
\hline 16 & 88 & 5.00 & 4.00 & 2.00 & 5.00 & 4.00 & 2.00 \\
\hline 17 & 95 & 4.00 & 4.00 & 2.00 & 5.00 & 4.00 & 2.00 \\
\hline 18 & 87 & 3.00 & 3.00 & 2.00 & 3.00 & 4.00 & 2.00 \\
\hline 19 & 92 & 4.00 & 4.00 & 2.00 & 5.00 & 4.00 & 2.00 \\
\hline 20 & 96 & 5.00 & 4.00 & 2.00 & 5.00 & 4.00 & 2.00 \\
\hline 21 & 90 & 4.00 & 4.00 & 2.00 & 5.00 & 4.00 & 2.00 \\
\hline 22 & 88 & 4.00 & 4.00 & 2.00 & 5.00 & 4.00 & 2.00 \\
\hline 23 & 94 & 4.00 & 4.00 & 2.00 & 5.00 & 4.00 & 2.00 \\
\hline 24 & 93 & 5.00 & 4.00 & 2.00 & 5.00 & 4.00 & 2.00 \\
\hline 25 & 88 & 5.00 & 4.00 & 2.00 & 5.00 & 4.00 & 2.00 \\
\hline 26 & 88 & 5.00 & 4.00 & 2.25 & 5.00 & 4.00 & 3.00 \\
\hline 27 & 89 & 5.00 & 4.00 & 2.00 & 5.00 & 4.00 & 2.00 \\
\hline 28 & 87 & 4.00 & 4.00 & 2.00 & 5.00 & 3.00 & 3.00 \\
\hline 29 & 88 & 5.00 & 4.00 & 2.00 & 5.00 & 4.00 & 2.00 \\
\hline 30 & 96 & 5.00 & 4.00 & 3.00 & 5.00 & 4.00 & 3.00 \\
\hline 31 & 89 & 5.00 & 4.00 & 2.00 & 5.00 & 4.00 & 2.00 \\
\hline 32 & 96 & 4.00 & 4.00 & 2.00 & 5.00 & 4.00 & 2.00 \\
\hline 33 & 93 & 5.00 & 4.00 & 2.00 & 5.00 & 4.00 & 2.00 \\
\hline 34 & 90 & 4.00 & 4.00 & 3.00 & 5.00 & 4.00 & 2.00 \\
\hline 35 & 87 & 5.00 & 4.00 & 2.00 & 4.00 & 4.00 & 2.00 \\
\hline
\end{tabular}

As can be noted from the table, for some videos the Medians or Modi are different than for other videos. For the comfort level, the median is 3.50 for video 7 and 3.00 for video 18 . In these videos, respectively, a left turn (T-junction) in a narrow corridor in an older part of the hospital and a right turn (T-junction) in a narrow corridor in a newer building are presented. Note that only for video 2 the median for confusion level is 5.00. This video depicts a right turn in a bright wide and clean corridor.

\subsection{Differences between Groups}

The Kruskal-Wallis $\mathrm{H}$ coefficient was calculated to check whether the responses were different for the different groups (Table 5). The videos were grouped per building (UZ, Plateau, Tweekerken/Hoveniers, Dunant) and per type (Simple L-turn, T-junctions, Open space, Doors, Stairs). 
The ratings of the different groups were compared, and surprisingly, no significant differences were detected for the grouping variable building for both comfort and confusion ratings. Moreover, the test detected, for the confusion ratings grouped by type, statistically significant differences between one or more groups. For comfort ratings, no statistically significant differences were detected. Conversely, for the separate videos (i.e., navigation situations), the Kruskal-Wallis H detected a significant difference between the ratings, both for comfort rating as for confusion rating.

Table 5. Results of the Kruskal-Wallis test.

\begin{tabular}{|c|c|c|c|c|c|c|c|c|c|c|}
\hline \multirow{2}{*}{ Variable } & \multirow{2}{*}{ Groups } & \multirow{2}{*}{ df } & \multicolumn{4}{|c|}{ Comfort } & \multicolumn{4}{|c|}{ Confusion } \\
\hline & & & $\mathbf{n}$ & Mean Rank & $\mathbf{H}$ & $\mathbf{p}$ & $\mathbf{n}$ & Mean Rank & $\mathbf{H}$ & $\mathbf{p}$ \\
\hline \multirow[t]{5}{*}{ Building } & & 3 & & & 2.573 & 0.462 & & & 1.886 & 0.596 \\
\hline & UZ & & 1088 & 160,604 & & & 1087 & 161,193 & & \\
\hline & Plateau & & 911 & 159,611 & & & 910 & 158,734 & & \\
\hline & Tweek./Hoven & & 909 & 154,803 & & & 910 & 156,682 & & \\
\hline & Dunant & & 265 & 161,117 & & & 265 & 154,692 & & \\
\hline \multirow[t]{6}{*}{ Type } & & 4 & & & 9.009 & 0.061 & & & 10.022 & 0.040 * \\
\hline & Simple L- turn & & 909 & 159,769 & & & 908 & 159,272 & & \\
\hline & T-junction & & 639 & 153,592 & & & 640 & 157,363 & & \\
\hline & Open space & & 802 & 159,257 & & & 801 & 155,808 & & \\
\hline & Doors & & 361 & 169,592 & & & 361 & 171,586 & & \\
\hline & Stairs & & 462 & 154,184 & & & 462 & 15,403 & & \\
\hline \multirow[t]{36}{*}{ Video } & & 34 & & & 73.152 & 0.000 * & & & 84.144 & 0.000 * \\
\hline & 1 & & 84 & 171,645 & & & 84 & 180,145 & & \\
\hline & 2 & & 85 & 180,636 & & & 85 & 189,173 & & \\
\hline & 3 & & 95 & 169,181 & & & 95 & 182,292 & & \\
\hline & 4 & & 89 & 168,957 & & & 89 & 162,405 & & \\
\hline & 5 & & 91 & 190,634 & & & 90 & 183,524 & & \\
\hline & 6 & & 90 & 166,712 & & & 90 & 160,959 & & \\
\hline & 7 & & 96 & 140,509 & & & 96 & 147,566 & & \\
\hline & 8 & & 89 & 148,748 & & & 89 & 131,274 & & \\
\hline & 9 & & 93 & 151,237 & & & 93 & 163,983 & & \\
\hline & 10 & & 93 & 151,621 & & & 93 & 151,101 & & \\
\hline & 11 & & 95 & 152,471 & & & 95 & 143,338 & & \\
\hline & 12 & & 88 & 137,795 & & & 88 & 141,584 & & \\
\hline & 13 & & 87 & 157,821 & & & 87 & 135,057 & & \\
\hline & 14 & & 95 & 153,394 & & & 95 & 14,985 & & \\
\hline & 15 & & 90 & 168,946 & & & 90 & 168,843 & & \\
\hline & 16 & & 88 & 173,769 & & & 88 & 176,066 & & \\
\hline & 17 & & 94 & 144,436 & & & 95 & 152,309 & & \\
\hline & 18 & & 87 & 137,456 & & & 87 & 144,061 & & \\
\hline & 19 & & 92 & 166,163 & & & 92 & 174,955 & & \\
\hline & 20 & & 96 & 171,671 & & & 96 & 16,938 & & \\
\hline & 21 & & 90 & 15,599 & & & 90 & 164,665 & & \\
\hline & 22 & & 88 & 151,913 & & & 88 & 165,933 & & \\
\hline & 23 & & 94 & 152,862 & & & 94 & 150,466 & & \\
\hline & 24 & & 93 & 149,222 & & & 93 & 145,269 & & \\
\hline & 25 & & 88 & 174,111 & & & 88 & 161,342 & & \\
\hline & 26 & & 88 & 143,472 & & & 88 & 143,657 & & \\
\hline & 27 & & 89 & 165,717 & & & 89 & 159,026 & & \\
\hline & 28 & & 87 & 147,566 & & & 87 & 138,801 & & \\
\hline & 29 & & 88 & 169,549 & & & 88 & 159,888 & & \\
\hline & 30 & & 96 & 144,796 & & & 96 & 152,119 & & \\
\hline & 31 & & 89 & 180,312 & & & 89 & 181,622 & & \\
\hline & 32 & & 96 & 156,728 & & & 96 & 161,325 & & \\
\hline & 33 & & 93 & 153,668 & & & 93 & 157,226 & & \\
\hline & 34 & & 90 & 139,019 & & & 89 & 153,021 & & \\
\hline & 35 & & 87 & 170,223 & & & 87 & 152,599 & & \\
\hline
\end{tabular}

* Significant on the $95 \%$ confidence level.

Since significant differences between the groups determined by type and video were detected for confusion and/or comfort ratings (Table 5), a post hoc Dunn test was performed to determine which groups were different from each other. The test statistics of the Dunn test for the confusion ratings on the videos grouped by type are presented in Table 6 . This test revealed significant differences between 
the ratings for the videos where open spaces were represented, and the ones were doors played a role. The videos depicting doors and the ones with stairs were also rated significantly differently by the participants. From the mean rank values in Table 5, it can be deduced that the videos with doors were rated less confusing than the ones with open spaces and stairs.

Table 6. Test statistics $\mathrm{Z}$ of post hoc Dunn test for confusion ratings on the videos grouped per type.

\begin{tabular}{cccccc}
\hline & Simple L-Turn & T-Junction & Open Space & Doors & Stairs \\
\hline Simple L-turn & & 19.09 & 34.64 & -123.14 & 52.41 \\
T-junction & & 15.55 & -142.23 & 33.33 \\
Open space & & & $-157.79 *$ & 17.77 \\
Doors & & & & $175.56^{*}$ \\
Stairs & & & & & \\
\hline
\end{tabular}

* Significant on the $95 \%$ confidence level.

For the ratings grouped per video, the Kruskal-Wallis test detected significant differences for the comfort and confusion ratings. The post hoc pairwise comparisons of the comfort level for the different videos revealed significant differences between video 5 and respectively, video 18, video 12 and video 34. For confusion level, the differences between video 8 and 5, 8 and 2, and 13 and 2 are significant. These results are presented in Table 7.

Table 7. Statistically significant results of the post hoc Dunn test of the ratings grouped per video.

\begin{tabular}{ccc}
\hline Comparisons Video & $\mathbf{Z}$ & $\begin{array}{c}\text { Adjusted } \mathbf{p} \\
\end{array}$ \\
\hline & Comfort \\
\hline $18-5$ & 531.8 & 0.035 \\
$12-5$ & 528.4 & 0.037 \\
$34-5$ & 516.1 & 0.05 \\
\hline & \multicolumn{2}{c}{ Confusion } \\
\hline $8-2$ & 579 & 0.009 \\
$13-2$ & 541.2 & 0.035 \\
$8-5$ & 522.5 & 0.045 \\
\hline
\end{tabular}

Apparent differences can be observed between the situations depicted in the videos that were rated differently for comfort:

- In video 18 a rather straightforward right turn (T-junction) is depicted in a narrow corridor.

- In video 12, a similar right turn is depicted but the corridor is wider and there is visual clutter (i.e., number and organization of objects in a scene [102]) present (several doors, cleaning gear, parked bike).

- In video 34, a courtyard is crossed but the doors providing access to the courtyard had to be opened manually.

In video 5 a right turn in a bright wide and clean corridor was presented. A contrast can thus be detected between the situations in the three videos and the one in video 5 .

For confusion ratings, a significant difference was detected for videos 8 and 13, with the same for video 5 and for video 2, where a left turn (T-junction) was depicted in a wide but somewhat darker corridor.

- In video 8, a simple right turn is presented in a narrow corridor in an older part of the building.

- In video 13, stairs are walked down, also cleaning gear and cabinets were captured on camera. 


\section{Discussion}

\subsection{Data Acquisition}

The online survey was published on Amazon Mechanical Turk to reach a varied public. A substantial amount of the submitted data was rejected (36.1\%). One could argue that the data is of low quality, but also the strict rejection process plays a role in this. Moreover, a large proportion of the participants had a high level of education ("academic degree"). Although this might be strange, similar to Ipeirotis [103], there were no incentives in our study to bias the participants towards lying, although false disclosure might occur. Nevertheless, the higher education level can be partially explained by the younger age of Mechanical Turk workers and higher education levels among technology users [104]. Moreover, Amazon Mechanical Turk has proved to be a valuable method $[105,106]$.

\subsection{Motives}

About one-third of the most frequently mentioned words, both for comfort rating and confusion rating, had a spatial component. However, the most interesting finding was that a discrepancy can be noted between the comfort and the confusion ratings. Participants referred more to words with a spatial component when evaluating confusion. In contrast, when evaluating comfort level, more non-spatial descriptions were used to motivate their ranking. These spatial categories capture the physical environment of the situations, while the non-spatial categories describe less tangible elements of the environment and the interpretation of it by the participants. These findings suggest that to make less confusing paths we can thus focus on the physical environment. Quantifying the complexity of decision points based on the characteristics of the physical environment has already been done in previous research in different ways (e.g., intersection complexity by the number of branches). Other researchers have employed space syntax or isovist measures to determine the complexity of decision points, and also included visibility and connectivity in the complexity quantification besides the building characteristics of decision points $[98,99,107,108]$. The results also indicate that, to create more comfortable paths, not only the structure of the physical environment but also other factors have to be integrated into the route planning algorithm. These findings might be in line with the positions of multiple scholars who argue that the effect of other people influences wayfinding [109-112] and that colors and illumination can facilitate navigation [113,114].

\subsection{Differences between the Groups}

\subsubsection{Building}

Surprisingly, for the grouping variable building, no significant differences were detected. The results show that the building's specific visual appearance has no substantial influence on both the comfort and the confusion ratings of the situations depicted in the videos. Although it is known that the legibility (i.e., the extent to which a building facilitates wayfinding [63]) of the building plays a role in indoor wayfinding, it was not reflected in the results. This is somewhat unexpected since the aspects that determine the legibility of a building (e.g., the signage, visible accessibility and the differentiation of the environment) are represented in the videos. A possible explanation is that legibility was not sufficiently represented in the videos. This might not be reflected in the separated wayfinding situations, although it is common to quantify both global and local legibility [98].

\subsubsection{Type}

For the ratings grouped by type, surprisingly no evidence was found to conclude that the situations affect comfort perception. The results do not show a significant difference between the comfort ratings of the videos representing turns, open spaces, doors, and stairs. Only significant differences were detected for confusion ratings. The videos with doors were rated less confusing than the ones with 
stairs and open spaces. This finding suggests that passing through doors is not as confusing as the other situations, and likewise, stairs and open spaces are more confusing.

Although attention has been devoted to these three aspects in research on indoor navigation, as outlined in Section 2.3, it is not always clear how they affect the wayfinding experience. Firstly, the effect of passing through doorways on the wayfinding experience, for instance, has not been actively researched so far. One of the participants in the focus group brought up that doors create boundary experiences. The boundary it creates has to be crossed when one has to leave a room to enter a new room. These boundaries can be soft (open door) or hard (closed) or something in between (if they are made from glass or they open automatically for instance). Secondly, since open spaces were rated as more confusing in our study, our results do not support the idea that the vistas in these open spaces enable legibility and support orientation. Moreover, from the focus group discussions, it could be concluded that these freely movable open spaces have an ambiguous effect on the navigation experience. Participants in the focus group argued that these spaces were experienced as pleasant or enjoyable. But according to the same participants, these spaces might also be vague and induce uncertainty while navigating. As can be noted, experience and theory about open spaces are somewhat inconsistent, and therefore the impact on open spaces in indoor wayfinding experiences is an important issue for further research. Thirdly, stairs are seen as a major source of wayfinding errors and avoiding them is also often included in path planning for the mobility impaired. It is thus generally accepted that stairs should be included in a route planning algorithm. In our subsequent study, we will try to further investigate the effect of these situations on the indoor wayfinding experience.

\subsubsection{Videos}

For the ratings grouped per video, the Kruskal-Wallis test detected significant differences between the ratings both for comfort and confusion. The subsequent post hoc pairwise comparisons, both for comfort and confusion level for the different videos, revealed significant differences between multiple videos. Both video 2 and video 5 were rated as less confusing, but only video 5 was rated more comfortably. The two videos depict a simple turn in a wide corridor, but video 5 was a brighter corridor. In addition, for video 5, which was rated more comfortable, there was less disagreement between the participants than for other videos (low IQR). Furthermore, for confusion ratings, video 2 is the only video with the highest median of 5.00. It seems possible that the confusion level might be related to the width of the corridor, but further work is required to establish this. Moreover, only the brighter corridor was rated higher for comfort, suggesting that illumination is a contributing factor. Also, Vilar et al. [115] concluded that wider and more illuminated routes were preferred.

\subsection{Limitations of the Study and Future Work}

Finally, a number of limitations of the current study need to be considered. First, the variables presented in the videos were as controlled as possible. Of course, other environmental characteristics cannot be controlled in the real environment. Second, the results of studying cognitive processes during navigation, based on virtual stimuli, are not completely accurate. In a well-controlled lab environment, body-movement is eliminated, as are real-world perceptions that have a substantial impact on information processing and spatial decision making [116]. Moreover, the study solely focused on several separate situations (and thus the environment) and neither the consecutive decision-making process nor the navigation aid were included in the study.

To overcome these problems, a subsequent experiment recording eye-tracking, while people are navigating along the entire route in a real indoor environment, has been planned to validate the results of the focus group and online survey. The design of the developed study is in line with the experimental designs in previous wayfinding studies $[26,117]$. Participants were guided in different complex buildings along different paths (i.e., the shortest path and path with fewest turns). The obtained data will provide insights into cognitive load and complexity perception across different paths and decision points. This knowledge could lead to a better understanding of how and on which occasions people 
make wayfinding errors. Moreover, complex routes and environmental characteristics that increase the complexity could be identified in this study.

The implementation of the findings of this paper and those of the subsequent study is subject to future work. These findings have to be translated into spatial concepts, which in turn have to be derivable from the spatial model. It is important to note that the spatial conceptualization of the findings should respect the characteristics of the chosen spatial model. Since the node creation theorems differ between the different network models (e.g., geometric network model, center-node network model, cell-decomposed networks and visibility-based network models), nodes are dissimilar in the various networks for the same space. Consequently, the chosen spatial model highly affects the results of the implemented guidance algorithms $[93,118]$. Moreover, the findings will be integrated into an existing algorithmic structure of an outdoor route calculation algorithm (e.g., the hierarchical path [119], the minimized route complexity path [42,120], the most reliable path [121], and minimizing the risk of getting lost [122]). As these were developed with outdoor network models in mind, these algorithms also have to be adapted to the indoor network model employed. Given these points, the effects of the spatial model need to be considered for the integration of our findings into the structure of an existing outdoor route planning algorithm.

\section{Conclusions}

Guiding people along easier-to-follow paths could improve indoor navigation systems. To develop better navigation support, and more specifically, the route planning aspect, this study examined the aspects potentially to be integrated into the route planning algorithms by applying a mixed-method approach. From the exploratory focus group discussion, it could be concluded that wayfinding research should be considered on different levels. The wayfinding experience might be affected by global (related to the route structure or overall building layout) and local building characteristics. In the second phase, the online survey focused solely on these local building characteristics. Participants were asked to rank their comfort level and confusion level towards the situations presented in the videos, and they had to provide their motivation for their rankings. The analysis of the motives exposed a discrepancy between the motives used for comfort and confusion ratings. When motivating confusion ratings, participants used more spatial components than when motivating comfort ratings. Moreover, results indicate that the appearance of the building did not have an influence on the comfort and confusion perception during navigation. Also, no statistically significant evidence was found for the influence of the different types on comfort perception. This result might be explained by the fact that the current investigation was limited to the separate situations depicted in the videos and the fact that real-world perceptions were eliminated. Further studies on this topic are therefore recommended. For confusion perception, our study has shown that situations that involve doors are less confusing than the ones with open spaces and stairs. In general, therefore, it seems that to make routes less confusing, open spaces and stairs need to be taken into account. In the future, a real-life experiment recording eye-tracking data will provide the ecological validity of our results presented in this paper. The implementation of these findings in a cognitively-sounding route algorithm will improve indoor wayfinding support.

Author Contributions: Conceptualization, Nina Vanhaeren and Kristien Ooms; Data curation, Nina Vanhaeren; Formal analysis, Nina Vanhaeren; Funding acquisition, Nina Vanhaeren; Investigation, Nina Vanhaeren; Methodology, Nina Vanhaeren and Kristien Ooms; Supervision, Kristien Ooms and Philippe De Maeyer; Validation, Nina Vanhaeren; Visualization, Nina Vanhaeren; Writing—original draft, Nina Vanhaeren; Writing—review \& editing, Nina Vanhaeren, Nico Van de Weghe, Laure De Cock, Lieselot Lapon, Kristien Ooms and Philippe De Maeyer. All authors have read and agreed to the published version of the manuscript.

Funding: This research was funded by Fonds Wetenschappelijk Onderzoek, grant number 1154219N.

Acknowledgments: This research has benefitted from a statistical consult with Ghent University FIRE (Fostering Innovative Research based on Evidence). 
Conflicts of Interest: The authors declare no conflict of interest. The funders had no role in the design of the study; in the collection, analyses, or interpretation of data; in the writing of the manuscript, or in the decision to publish the results.

\section{References}

1. Ahmetovic, D.; Gleason, C.; Ruan, C.; Kitani, K.; Takagi, H.; Asakawa, C. NavCog: A navigational cognitive assistant for the blind. In Proceedings of the 18th International Conference on Human-Computer Interaction with Mobile Devices and Services, Florence, Italy, 9 September 2016; pp. 90-99.

2. Cheraghi, S.A.; Sharma, A.; Namboodiri, V.; Arsal, G. SafeExit4AII. In Proceedings of the 16th International Web for All Conference, San Francisco, CA, USA, 13-15 May 2019; pp. 1-10.

3. Biczok, G.; Diez Martinez, S.; Jelle, T.; Krogstie, J. Navigating MazeMap: Indoor human mobility, spatio-logical ties and future potential. In Proceedings of the IEEE International Conference on Pervasive Computing and Communication Workshops, Budapest, Hungary, 24-28 March 2014; pp. 266-271.

4. Helal, A.; Moore, S.E.; Ramachandran, B. Drishti: An integrated navigation system for visually impaired and disabled. In Proceedings of the Fifth International Symposium on Wearable Computers, Zurich, Switzerland, 8-9 October 2001; pp. 149-156.

5. Kishore, A.; Bhasin, A.; Balaji, A.; Vuppalapati, C.; Jadav, D.; Anantharaman, P.; Gangras, S. CENSE: A cognitive navigation system for people with special needs. In Proceedings of the IEEE Third International Conference on Big Data Computing Service and Applications, San Francisco, CA, USA, 6-9 April 2017; pp. 198-203.

6. Chen, J.; Ou, G.; Peng, A.; Zheng, L.; Shi, J. An INS/floor-plan indoor localization system using the firefly particle filter. ISPRS Int. J. Geo-Inf. 2018, 7, 324. [CrossRef]

7. Feng, G.; Ma, L.; Tan, X.; Qin, D. Drift-aware monocular localization based on a pre-constructed dense 3D map in indoor environments. ISPRS Int. J. Geo-Inf. 2018, 7, 299. [CrossRef]

8. Jing, C.; Wang, S.; Wang, M.; Du, M.; Zhou, L.; Sun, T.; Wang, J. A low-cost collaborative location scheme with GNSS and RFID for the Internet of things. ISPRS Int. J. Geo-Inf. 2018, 7, 180. [CrossRef]

9. Ebner, F.; Fetzer, T.; Deinzer, F.; Grzegorzek, M. On Wi-Fi model optimizations for smartphone-based indoor localization. ISPRS Int. J. Geo-Inf. 2017, 6, 233. [CrossRef]

10. Zhou, Y.; Zheng, X.; Xiong, H.; Chen, R. Robust indoor mobile localization with a semantic augmented route network graph. ISPRS Int. J. Geo-Inf. 2017, 6, 221. [CrossRef]

11. Chiang, K.W.; Liao, J.K.; Huang, S.H.; Chang, H.W.; Chu, C.H. The performance analysis of space resection-aided pedestrian dead reckoning for smartphone navigation in a mapped indoor environment. ISPRS Int. J. Geo-Inf. 2017, 6, 43. [CrossRef]

12. Lai, Y.C.; Chang, C.C.; Tsai, C.M.; Huang, S.C.; Chiang, K.W. A knowledge-based step length estimation method based on fuzzy logic and multi-sensor fusion algorithms for a pedestrian dead reckoning system. ISPRS Int. J. Geo-Inf. 2016, 5, 70. [CrossRef]

13. Li, X.; Wang, J.; Liu, C.; Zhang, L.; Li, Z. Integrated WiFi/PDR/Smartphone using an adaptive system noise extended kalman filter algorithm for indoor localization. ISPRS Int. J. Geo-Inf. 2016, 5, 8. [CrossRef]

14. Li, X.; Wang, J.; Liu, C. Heading estimation with real-time compensation based on kalman filter algorithm for an indoor positioning system. ISPRS Int. J. Geo-Inf. 2016, 5, 98. [CrossRef]

15. Li, Z.; Liu, C.; Gao, J.; Li, X. An improved WiFi/PDR integrated system using an adaptive and robust filter for indoor localization. ISPRS Int. J. Geo-Inf. 2016, 5, 224. [CrossRef]

16. Pang, Y.; Zhang, C.; Zhou, L.; Lin, B.; Lv, G. Extracting indoor space information in complex building environments. ISPRS Int. J. Geo-Inf. 2018, 7, 321. [CrossRef]

17. Lewandowicz, E.; Lisowski, P.; Flisek, P. A modified methodology for generating indoor navigation models. ISPRS Int. J. Geo-Inf. 2019, 8, 60. [CrossRef]

18. Worboys, M. Modeling indoor space. In Proceedings of the 3rd International Workshop, Chicago, IL, USA, 1 November 2011; pp. 1-6.

19. Diakité, A.A.; Zlatanova, S. Spatial subdivision of complex indoor environments for 3D indoor navigation. Int. J. Geogr. Inf. Sci. 2018, 32, 213-235. [CrossRef] 
20. Kondyli, V.; Schultz, C.; Bhatt, M. Evidence-based parametric design: Computationally generated spatial morphologies satisfying behavioural-based design constraints. In Proceedings of the 13th International Conference on Spatial Information Theory, L'Aquila, Italy, 4-8 September 2017; Volume 86, pp. 1-11.

21. Kondyli, V.; Bhatt, M.; Hartmann, T. Precedent based design foundations for parametric design. Adv. Comput. Des. 2018, 3, 30 .

22. Hunter, S. Architectural wayfinding. Des. Resour. 2010, 8, 1-6.

23. Aboim Borges, M.; Silva, F. User-sensing as part of a wayfinding design process. Procedia Manuf. 2015, 3, 5912-5919. [CrossRef]

24. Manning, J.R.; Lew, T.F.; Li, N.; Sekuler, R.; Kahana, M.J. MAGELLAN: A cognitive map-based model of human wayfinding. J. Exp. Psychol. Gen. 2014, 143, 1314-1330. [CrossRef]

25. Raubal, M.; Worboys, M. A formal model of the process of wayfinding in built environments. Spat. Inf. Theory Cogn. Comput. Found. Geogr. Inf. Sci. 1999, 1661, 381-399.

26. Hölscher, C.; Meilinger, T.; Vrachliotis, G.; Brösamle, M.; Knauff, M. Finding the way inside: Linking architectural design analysis and cognitive processes. In Spatial Cognition IV, Reasoning, Action, Interaction; Freksa, C., Knauff, M., Krieg-Brückner, B., Nebel, B., Barkowsky, T.H., Eds.; Springer: Berlin/Heidelberg, Germany, 2005; Volume 3343, pp. 1-12.

27. Golledge, R.G.; Jacobson, R.D.; Kitchin, R.; Blades, M. Cognitive maps, spatial abilities and human wayfinding. Geogr. Rev. Jpn. Ser. B 2000, 73, 93-104. [CrossRef]

28. Epstein, R.A.; Patai, E.Z.; Julian, J.B.; Spiers, H.J. The cognitive map in humans: Spatial navigation and beyond. Nat. Neurosci. 2017, 20, 1504-1513. [CrossRef]

29. Kannan, B.; Kothari, N.; Gnegy, C.; Gedaway, H.; Dias, M.F.; Dias, M.B. Localization, route planning, and smartphone interface for indoor navigation. In Cooperative Robots and Sensor Networks (Studies in Computational Intelligence); Koubâa, A., Khelil, A., Eds.; Springer: Berlin/Heidelberg, Germany, 2014; Volume 507, pp. 39-59.

30. Štefanička, T.; Ďuračiová, R.; Seres, C. Development of a web-based indoor navigation system using an accelerometer and gyroscope: A case study at the faculty of natural sciences of comenius university. Slovak J. Civ. Eng. 2017, 25, 47-56. [CrossRef]

31. Martinez-Sala, A.; Losilla, F.; Sánchez-Aarnoutse, J.; García-Haro, J. Design, implementation and evaluation of an indoor navigation system for visually impaired people. Sensors 2015, 15, 32168-32187. [CrossRef] [PubMed]

32. Li, Y.; Park, J.-H.; Shin, B.-S. A shortest path planning algorithm for cloud computing environment based on multi-access point topology analysis for complex indoor spaces. J. Supercomput. 2017, 73, 2867-2880. [CrossRef]

33. Teo, T.A.; Cho, K.H. BIM-oriented indoor network model for indoor and outdoor combined route planning. Adv. Eng. Inform. 2016, 30, 268-282. [CrossRef]

34. Ali, H.M.; Noori, Z.T. Indoor way finder navigation system using smartphone. Int. J. Comput. Sci. Mob. Comput. 2016, 5, 202-218.

35. Khan, A.A.; Yao, Z.; Kolbe, T.H. Context aware indoor route planning using semantic 3D building models with cloud computing. In 3D Geoinformation Science; Springer: Berlin/Heidelberg, Germany, 2015; pp. 175-192.

36. Delnevo, G.; Monti, L.; Vignola, F.; Salomoni, P.; Mirri, S. AlmaWhere: A prototype of accessible indoor wayfinding and navigation system. In Proceedings of the 15th IEEE Annual Consumer Communications \& Networking Conference (CCNC), Las Vegas, NV, USA, 12-15 January 2018; pp. 1-6.

37. Yuan, W.; Schneider, M. Geospatial Thinking; Springer: Berlin/Heidelberg, Germany, 2010.

38. Warren, W.H. Non-euclidean navigation. J. Exp. Biol. 2019, 222. [CrossRef]

39. Müller, M.; Ohm, C.; Schwappach, F.; Ludwig, B. The path of least resistance. Künstl. Intell. 2017, 31, $125-134$.

40. Hillier, B.; Iida, S. Network and psychological effects: A theory of urban movement. In Spatial Information Theory; COSIT 2005; Lecture Notes in Computer Science; Cohn, A.G., Mark, D.M., Eds.; Springer: Berlin/Heidelberg, Germany, 2005; Volume 3693, pp. 475-490.

41. Jiang, B.; Liu, X. Computing the fewest-turn map directions based on the connectivity of natural roads. Int. J. Geogr. Inf. Sci. 2011, 25, 1069-1082. [CrossRef] 
42. Duckham, M.; Kulik, L. "Simplest" paths: Automated route selection for navigation. In Spatial Information Theory; Foundations of Geographic Information Science; COSIT 2003; Lecture Notes in Computer Science; Kuhn, W., Worboys, F.M., Timpf, S., Eds.; Springer: Berlin/Heidelberg, Germany, 2003; Volume 2825, pp. 169-185.

43. Wang, J.; Zhao, H.; Winter, S. Integrating sensing, routing and timing for indoor evacuation. Fire Saf. J. 2015, 78, 111-121. [CrossRef]

44. Park, I.; Jang, G.U.; Park, S.; Lee, J. Time-dependent optimal routing in micro-scale emergency situation. In Proceedings of the Tenth International Conference on Mobile Data Management: Systems, Services and Middleware, Taipei, Taiwan, 18-20 May 2009; pp. 714-719.

45. Swobodzinski, M.; Raubal, M. An indoor routing algorithm for the blind: Development and comparison to a routing algorithm for the sighted. Int. J. Geogr. Inf. Sci. 2009, 23, 1315-1343. [CrossRef]

46. Kahale, E.; Hanse, P.C.; Destin, V.; Uzan, G.; Lopez-Krahe, J. Path planning for a universal indoor navigation system. In Lecture Notes in Computer Science (Including Subseries Lecture Notes in Artificial Intelligence and Lecture Notes in Bioinformatics); Miesenberger, K., Buhler, C., Penaz, P., Eds.; Springer: Cham, Switzerland, 2016; Volume 9759, pp. 190-197.

47. Dudas, P.M.; Ghafourian, M.; Karimi, H.A. ONALIN: Ontology and algorithm for indoor routing. In Proceedings of the Tenth International Conference on Mobile Data Management: Systems, Services and Middleware, Taipei, Taiwan, 18-20 May 2009; pp. 720-725.

48. Zhou, Y.; Chen, H.; Huang, Y.; Luo, Y.; Zhang, Y.; Xie, X. An indoor route planning method with environment awareness. Int. Geosci. Remote Sens. Symp. 2018. [CrossRef]

49. Farr, A.C.; Kleinschmidt, T.; Yarlagadda, P.; Mengersen, K. Wayfinding: A simple concept, a complex process. Transp. Rev. 2012, 32, 715-743. [CrossRef]

50. Wiener, J.M.; Büchner, S.J.; Hölscher, C. Taxonomy of human wayfinding tasks: A knowledge-based approach. Spat. Cogn. Comput. 2009, 9, 152-165. [CrossRef]

51. Montello, D.R. Navigation. In The Cambridge Handbook of Visuospatial Thinking; Shah, P., Miyake, A., Eds.; Cambridge University Press: New York, NY, USA, 2005; pp. 257-294. ISBN 9780521001731.

52. Spiers, H.; Maguire, E. The dynamic nature of cognition during wayfinding. J. Environ. Psychol. 2008, 28, 232-249. [CrossRef] [PubMed]

53. Zube, E.H. Environmental perception. In Environmental Geology; Springer: Dordrecht, The Netherlands, 1999; pp. 214-216. ISBN 978-1-4020-4494-6.

54. Erçevik Sönmez, B.; Erinsel Önder, D. The influence of GPS-based navigation systems on perception and image formation: A case study in urban environments. Cities 2019, 86, 102-112. [CrossRef]

55. Duckham, M.; Winter, S.; Robinson, M. Including landmarks in routing instructions. J. Locat. Based Serv. 2010, 4, 28-52. [CrossRef]

56. Hu, X.; Ding, L.; Shang, J.; Fan, H.; Novack, T.; Noskov, A.; Zipf, A. Data-driven approach to learning salience models of indoor landmarks by using genetic programming. Int. J. Digit. Earth 2020. [CrossRef]

57. Jukka, M.; Mathias Jahnke, H.L.; Krisp, F.F. A computational method for indoor landmark extraction. Programme Locat. Serv. 2014. [CrossRef]

58. Kattenbeck, M. Empirically measuring salience of objects for use in pedestrian navigation. In Proceedings of the 23rd Sigspatial International Conference on Advances in Geographic Information Systems, Washington, DC, USA, 3-6 November 2015.

59. Zhu, L.; Švedová, H.; Shen, J.; Stachoň, Z.; Shi, J.; Snopková, D.; Li, X. An instance-based scoring system for indoor landmark salience evaluation. Geogr. CGS 2019, 124, 103-131. [CrossRef]

60. Brunyé, T.T.; Gardony, A.L.; Holmes, A.; Taylor, H.A. Spatial decision dynamics during wayfinding: Intersections prompt the decision-making process. Cogn. Res. Princ. Implic. 2018, 3. [CrossRef]

61. Nasir, M.; Nahavandi, S.; Creighton, D. Fuzzy simulation of pedestrian walking path considering local environmental stimuli. In Proceedings of the IEEE International Conference on Fuzzy Systems, Brisbane, Australia, 10-15 June 2012.

62. Kuliga, S.; Nelligan, B.; Dalton, R.; Marchette, S.; Shelton, A.; Carlson, L.; Hölscher, C. Exploring individual differences and building complexity in wayfinding: The case of the seattle central library. Environ. Behav. 2019, 51, 1-51. [CrossRef]

63. Weisman, J. Evaluating architectural legibility: Way-finding in the built environment. Environ. Behav. 1981, 13, 189-204. [CrossRef] 
64. Ohno, R.; Kushiyama, N.; Soeda, M. Wayfinding in cases with vertical traveling. J. Arch. Plan. (Trans. AIJ) 1999, 64, 87-91. [CrossRef]

65. Carlson, L.A.; Hölscher, C.; Shipley, T.F.; Dalton, R.C. Getting lost in buildings. Curr. Dir. Psychol. Sci. 2010, 19, 284-289. [CrossRef]

66. Hölscher, C.; Meilinger, T.; Vrachliotis, G.; Brösamle, M.; Knauff, M. Up the down staircase: Wayfinding strategies in multi-level buildings. J. Environ. Psychol. 2006, 26, 284-299. [CrossRef]

67. Balaban, C.Z.; Karimpur, H.; Röser, F.; Hamburger, K. Turn left where you felt unhappy: How affect influences landmark-based wayfinding. Cogn. Process. 2017, 18, 135-144. [CrossRef]

68. Palmiero, M.; Nori, R.; Rogolino, C.; D'amico, S.; Piccardi, L. Sex differences in visuospatial and navigational working memory: The role of mood induced by background music. Exp. Brain Res. 2016, 234, 2381-2389. [CrossRef]

69. Huang, H.; Klettner, S.; Schmidt, M.; Gartner, G.; Leitinger, S.; Wagner, A.; Steinmann, R. AffectRoute-Considering people's affective responses to environments for enhancing route-planning services. Int. J. Geogr. Inf. Sci. 2014, 28, 2456-2473. [CrossRef]

70. Palmiero, M.; Piccardi, L. The role of emotional landmarks on topographical memory. Front. Psychol. 2017, 8, 1-8. [CrossRef]

71. Gartner, G. openemotionmap.org-Emotional response to space as an additional concept in cartography. ISPRS Int. Arch. Photogramm. Remote Sens. Spat. Inf. Sci. 2012. [CrossRef]

72. Lin, J.; Cao, L.; Li, N. Assessing the influence of repeated exposures and mental stress on human wayfinding performance in indoor environments using virtual reality technology. Adv. Eng. Inform. 2019, 39, 53-61. [CrossRef]

73. Hund, A.M.; Minarik, J.L. Getting from here to there: Spatial anxiety, wayfinding strategies, direction type, and wayfinding efficiency. Spat. Cogn. Comput. 2006, 6, 179-201. [CrossRef]

74. Slone, E.; Burles, F.; Robinson, K.; Levy, R.M.; Iaria, G. Floor plan connectivity influences wayfinding performance in virtual environments. Environ. Behav. 2015, 47, 1024-1053. [CrossRef]

75. Fogliaroni, P.; Bucher, D.; Jankovic, N.; Giannopoulos, I. Intersections of our world. Leibniz Int. Proc. Inform. Lipics 2018, 114, 1-15.

76. Ohm, C.; Müller, M.; Ludwig, B.; Bienk, S. Where is the landmark? Eye tracking studies in large-scale indoor environments. In Proceedings of the 2nd International Workshop on Eye Tracking for Spatial Research, Vienna, Austria, 23 September 2014; pp. 47-51.

77. Viaene, P.; Ooms, K.; Vansteenkiste, P.; Lenoir, M.; De Maeyer, P. The use of eye tracking in search of indoor landmarks. CEUR Workshop Proc. 2014, 1241, 52-56.

78. Goetz, M.; Zipf, A. Formal definition of a user-adaptive and length-optimal routing graph for complex indoor environments. Geo-Spat. Inf. Sci. 2011, 14, 119-128. [CrossRef]

79. Yuan, W.; Schneider, M. iNav: An indoor navigation model supporting length-dependent optimal routing. In Geospatial Thinking; Lecture Notes in Geoinformation and Cartography; Painho, M., Santos, M., Pundt, H., Eds.; Springer: Berlin/Heidelberg, Germany, 2010; pp. 299-313.

80. Liu, L.; Zlatanova, S. A “Door-to-door" path-finding approach for indoor navigation. In Proceedings of the Geoinformatics for Disaster Management, Antalya, Turkey, 3-8 May 2011; pp. 3-8.

81. Vanclooster, A.; Van de Weghe, N.; De Maeyer, P. Integrating indoor and outdoor spaces for pedestrian navigation guidance: A review. Trans. GIS 2016, 20, 491-525. [CrossRef]

82. Kalakou, S.; Moura, F. Bridging the gap in planning indoor pedestrian facilities. Transp. Rev. 2014, 34, 474-500. [CrossRef]

83. Hölscher, C.; Meilinger, T.; Vrachliotis, G.; Brösamle, M.; Knauff, M. Finding the way inside: Linking architectural design analysis and cognitive processes. Spat. Cogn. Comput. 2005, 3343, 1-12.

84. Dogu, U.; Erkip, F. Spatial factors affecting wayfinding and orientation: A case study in a shopping mall. Environ. Behav. 2000, 32, 731-755. [CrossRef]

85. Ortega-Andeane, P.; Jiménez-Rosas, E.; Mercado-Doménech, S.; Estrada-Rodríguez, C. Space syntax as a determinant of spatial orientation perception. Int. J. Psychol. 2005, 40, 11-18. [CrossRef]

86. Abu-Ghazzeh, T.M. Movement and wayfinding in the king saud university built environment: A look at freshman orientation and environmental information. J. Environ. Psychol. 1996, 16, 303-318. [CrossRef]

87. Hahmann, S.; Miksch, J.; Resch, B.; Lauer, J. Geo-spatial Information Science Routing through open spaces-A performance comparison of algorithms. Geo-Spat. Inf. Sci. 2018, 5020, 1-11. 
88. Vanclooster, A.; Vanhaeren, N.; Viaene, P.; Ooms, K.; De Cock, L.; Fack, V.; Van de Weghe, N.; De Maeyer, P. Turn calculations for the indoor application of the fewest turns path algorithm. Int. J. Geogr. Inf. Sci. 2019. [CrossRef]

89. Karimi, H.A.; Ghafourian, M. Indoor routing for individuals with special needs and preferences. Trans. GIS 2010, 14, 299-329. [CrossRef]

90. Lin, W.Y.; Lin, P.H. Intelligent generation of indoor topology (i-GIT) for human indoor pathfinding based on IFC models and 3D GIS technology. Autom. Constr. 2018, 94, 340-359. [CrossRef]

91. Fichtner, F.W.; Diakité, A.A.; Zlatanova, S.; Voûte, R. Semantic enrichment of octree structured point clouds for multi-story 3D pathfinding. Trans. GIS 2018, 22, 233-248. [CrossRef]

92. Verghote, A.; Al-Haddad, S.; Goodrum, P.; Van Emelen, S. The effects of information format and spatial cognition on individual wayfinding performance. Buildings 2019, 9, 29. [CrossRef]

93. Vanclooster, A.; Ooms, K.; Viaene, P.; Fack, V.; Van De Weghe, N.; De Maeyer, P. Evaluating suitability of the least risk path algorithm to support cognitive wayfinding in indoor spaces: An empirical study. Appl. Geogr. 2014, 53, 128-140. [CrossRef]

94. Nielsen, J. Usability Engineering; Morgan Kaufmann Publishers Inc.: San Francisco, CA, USA, 1994; ISBN 0125184050.

95. GPS for Enterprises. Available online: http://www.thinkkit.eu/en-gb/gps-for-enterprises/download (accessed on 16 November 2018).

96. Freitas, H.; Oliveira, M.; Jenkins, M.; Popjoy, O. The Focus Group, A Qualitative Research Method; ISRC: Baltimore, MD, USA, 1998.

97. Krueger, R.A.; Casey, M.A. Designing and conducting focus group interviews. In Social Analysis Selected Tools and Techniques; The World Bank: Washington, DC, USA, 2001; pp. 4-24. ISBN 00393665.

98. Li, R.; Klippel, A. Wayfinding behaviors in complex buildings: The impact of environmental legibility and familiarity. Environ. Behav. 2014. [CrossRef]

99. Emo, B. Choice zones: Architecturally relevant areas of interest. Spat. Cogn. Comput. 2018, 18, $173-193$. [CrossRef]

100. Van Someren, M.W.; Barnard, Y.F.; Sandberg, J.A. The Think Aloud Method: A Practical Guide to Modelling Cognitive Processes; Academic Press: London, UK, 1994; ISBN 0127142703.

101. Landis, J.R.; Koch, G.G. The measurement of observer agreement for categorical data. Biometrics 1977, 33, 159-174. [CrossRef]

102. Baltaretu, A.; Krahmer, E.; Maes, A. Improving route directions: The role of intersection type and visual clutter for spatial reference. Appl. Cogn. Psychol. 2015, 29, 647-660. [CrossRef]

103. Ipeirotis, P. Demographics of Mechanical Turk; CeDER-10-01 Working Paper; WSDM: Marina del Rey, CA, USA, 2010.

104. Paolacci, G.; Chandler, J.; Ipeirotis, P. Running experiments on amazon mechanical turk. Judgm. Decis. Mak. 2010, 5, 411-419.

105. Mason, W.; Suri, S. Conducting behavioral research on Amazon's Mechanical Turk. Behav. Res. Methods 2012, 44, 1-23. [CrossRef]

106. Ward-Ciesielski, E.F.; Winer, E.S.; Drapeau, C.W.; Nadorff, M.R. Examining components of emotion regulation in relation to sleep problems and suicide risk. J. Affect. Disord. 2018, 241, 41-48. [CrossRef]

107. Meilinger, T.; Franz, G.; Bülthoff, H.H. From isovists via mental representations to behaviour: First steps toward closing the causal chain. Environ. Plan. B Plan. Des. 2012, 39, 48-62. [CrossRef]

108. Li, R.; Klippel, A. Using space syntax to understand knowledge acquisition and wayfinding in indoor environments. In Proceedings of the 9th IEEE International Conference on Cognitive Informatics (ICCI), Beijing, China, 7-9 July 2010; pp. 302-307.

109. Dalton, R.C.; Hölscher, C.; Montello, D.R. Wayfinding as a social activity. Front. Psychol. 2019, 10, 1-14. [CrossRef]

110. Jazuk, K.; Panagiotis, M.; Thrash, T.; Victor, S.; Hoelscher, C. Social density and building layout: The experience of crowding in wayfinding. In Proceedings of the 7th International Conference on Spatial Cognition (ICSC), Roma, Italy, 10-14 September 2018.

111. Li, H.; Thrash, T.; Hölscher, C.; Schinazi, V.R. The effect of crowdedness on human wayfinding and locomotion in a multi-level virtual shopping mall. J. Environ. Psychol. 2019, 65, 101320. [CrossRef] 
112. Silva, C.; Rebelo, F.; Vilar, E.; Noriega, P. Preliminary study about social influence over wayfinding decisions. Procedia Manuf. 2015, 3, 5920-5926. [CrossRef]

113. Costa, M.; Frumento, S.; Nese, M.; Predieri, I. Interior color and psychological functioning in a university residence hall. Front. Psychol. 2018, 9, 1-13. [CrossRef] [PubMed]

114. Hidayetoglu, M.L.; Yildirim, K.; Akalin, A. The effects of color and light on indoor wayfinding and the evaluation of the perceived environment. J. Environ. Psychol. 2012, 32, 50-58. [CrossRef]

115. Vilar, E.; Teixeira, L.; Rebelo, F.; Noriega, P.; Teles, J. Using environmental affordances to direct people natural movement indoors. Work 2012, 41, 1149-1156. [CrossRef] [PubMed]

116. Schwarzkopf, S.; Von Stülpnagel, R. What lab eye tracking tells us about wayfinding a comparison of stationary and mobile eye tracking in a large building scenario. In Proceedings of the 1st International Workshop Eye Tracking for Spatial Research, Lille, France, 15-17 May 2013; pp. 31-36.

117. Hölscher, C.; Büchner, S.J.; Meilinger, T.; Strube, G. Adaptivity of wayfinding strategies in a multi-building ensemble: The effects of spatial structure, task requirements, and metric information. J. Environ. Psychol. 2009, 29, 208-219. [CrossRef]

118. Vanclooster, A.; Van de Weghe, N.; Fack, V.; De Maeyer, P. Comparing indoor and outdoor network models for automatically calculating turns. J. Locat. Based Serv. 2014, 8, 1-18. [CrossRef]

119. Fu, L.; Sun, D.; Rilett, L.R. Heuristic shortest path algorithms for transportation applications: State of the art. Comput. Oper. Res. 2006, 33, 3324-3343. [CrossRef]

120. Richter, K.; Duckham, M. Simplest instructions: Finding easy-to-describe. In Geographic Information Science; ; Lecture Notes in Computer Science; Cova, T.J., Miller, H.J., Beard, K., Frank, A.U., Goodchild, M.F., Eds.; Springer: Berlin/Heidelberg, Germany, 2008; Volume 5266, pp. 274-289.

121. Haque, S.; Kulik, L.; Klippel, A. Algorithms for reliable navigation and wayfinding. Spat. Cogn. 2006. [CrossRef]

122. Grum, E. Danger of getting lost: Optimize a path to minimize risk. In Proceedings of the 10th Symposion on Information \& Communication Technologies (ICT) in Urban Planning And Spatial Developement and Impacts of ICT on Physical Space, Vienna, Austria, 22-25 February 2005.

(C) 2020 by the authors. Licensee MDPI, Basel, Switzerland. This article is an open access article distributed under the terms and conditions of the Creative Commons Attribution (CC BY) license (http://creativecommons.org/licenses/by/4.0/). 